\title{
Adoção Homoparental e Preconceito: Crenças de Estudantes de Direito e Serviço Social
}

\author{
Elder Cerqueira-Santos ${ }^{1}$ \\ Geovanna Santana \\ Programa de Pós-Graduação em Psicologia Social da Universidade Federal de Sergipe, \\ São Cristóvão, SE, Brasil
}

\begin{abstract}
Resumo
Profissionais de direito e serviço social são atores fundamentais na implementação de novas práticas de adoção para casais homossexuais, no entanto, parecem carecer em sua formação sobre desenvolvimento e sexualidade humana para o processo de análise de casos. O objetivo desse estudo é investigar as crenças de estudantes de Direito e Serviço Social sobre orientação sexual e adoção homoparental. Participaram deste estudo 132 estudantes, sendo $67(49,2 \%)$ do curso de Serviço Social e $65(50,8 \%)$ do curso de Direito, todos de universidade federal pública, com media de idade de 25 anos $(D P=5,51)$. Foram aplicadas duas escalas padronizadas (crença sobre homossexualidade e crença sobre adoção homoparental), além disso, questionou-se sobre o contato e informação sobre homossexualidade. De maneira geral, os estudantes de serviço social apresentaram maiores percentuais para crenças positivas enquanto que os estudantes de direito apresentaram maiores percentuais para crenças negativas sobre homossexualidade em ambas escalas. A concordância da adoção encontrada em estudantes de direito foi de 61,01 enquanto serviço social obteve $68,87(t=12,27 ; p<0,001)$. Na escala de preconceito homossexual, os estudantes de direito obtiveram 22,80 e os estudantes de serviço social obtiveram $21,65(t=2,03 ; p=0,045)$. Há correlação entre as crenças e o contato e amizade com homossexuais. Este estudo observou que futuros profissionais, ainda demonstram pouco conhecimento sobre orientação sexual e consequências de adoção por casais homoafetivos.
\end{abstract}

Palavras-chave: Adoção, homoparentalidade, família, preconceito.

\section{Homoparental Adoption and Prejudice: Beliefs of Law and Social Service Students}

\begin{abstract}
Attorneys and social workers are key actors in implementing new practices for gay adoption, however, it seems to exist a lack of training on human development and sexuality during the decision-making process. The aim of this study is to investigate the belief of law and social worker students on sexual orientation and homoparental adoption. The study included 132 students, 67 (49.2\%) enrolled in Social Service major and $65(50.8 \%)$ in law, all from a public university, with mean age of 25 years $(S D=$ 5.51). Two scales were used (beliefs about homosexuality and homoparental adoption belief), moreover, it was asked about the contact and information about homosexuality. In general, social work students had

Endereço para correspondência: Universidade Federal de Sergipe, Departamento de Psicologia, Av. Marechal Rondon, s/n, Jardim Rosa Else, São Cristóvão, SE, Brasil 49020-330. E-mail: eldercerqueira@gmail.com e geovannasantana92@gmail.com

Financiamento: Conselho Nacional de Desenvolvimento Científico e Tecnológico (CNPq).
\end{abstract}


higher percentages for positive beliefs while law students had higher percentages for negative beliefs on both scales. The agreement found for the adoption among law students was 61.01 while social services got $68.87(t=12.27, p<.001)$. On the scale of homosexual prejudice, law students got 22.80 and social work students got $21.65(t=2.03, p=.045)$. There were found correlation between beliefs, interpersonal contact and friendship with homosexual. This study found that these future professionals yet have little knowledge about sexual orientation and consequences of adoption by homosexual couples.

Keywords: Adoption, homosexuality, family, prejudice.

\section{Adopción Homoparental y Prejuicio: Creencias de Estudiantes de Derecho y Servicio Social}

\section{Resumen}

Los profesionales de derecho y servicios sociales son actores clave en la implementación de nuevas prácticas de adopción para las parejas homosexuales, sin embargo, parece que falta en su formación contenido sobre desarrollo de la sexualidad humana. El objetivo de este estudio es investigar las creencias de estudiantes de derecho y servicios sociales acerca de la orientación sexual y adopción homoparental. Participaron 132 estudiantes, 67 (49.2\%) de Servicios Sociales y 65 (50.8\%) de la facultad de derecho, en una universidad federal pública, con edad media de 25 años $(S D=5.51)$. Se aplicaron dos escalas estándar (creencia acerca de la homosexualidad y creencia acerca de la adopción homoparental) también se les preguntó sobre el contacto y la información acerca de la homosexualidad. Los estudiantes de servicio social tuvieron porcentajes más altos por las creencias positivas, mientras que los estudiantes de derecho tuvieron porcentajes más altos para las creencias negativas sobre la homosexualidad en ambas escalas. La concordancia acerca de La adopción homosexual de los estudiantes de derecho era 61.01, mientras que el servicio social obtuvo $68.87(t=12.27, p<.001)$. En escala de perjuicio homosexual, los estudiantes de derecho obtuvieron 22.80 y de servicio social obtuvieron $21.65(t=2.03 ; p=.045)$. No existe correlación entre las creencias y el contacto y la amistad con los homosexuales. En este estudio se observó que los futuros profesionales aún tienen poco conocimiento acerca de la orientación sexual y las consecuencias de la adopción por parte de parejas homosexuales.

Palabras clave: Adopción, homoparentalidad, familia, prejuicio.

Vários estudos nacionais têm mostrado que o preconceito homofóbico é uma realidade que impede mais avanços para esta população (conforme revisado por Araújo, Oliveira, Sousa, \& Castanha, 2007 e Uziel, Mello, \& Grossi, 2006, além de estudos recentes de Freire \& Cardinali, 2012; Nardi \& Quartiero, 2012, entre outros). Da mesma forma, estudos internacionais identificam a relação entre uma cultura homofóbica, moralismo e exclusão de direitos para minorias sexuais (Baiocco, D’Alessio, \& Laghi, 2010; Butler, 2003; Herek, Gillis, \& Cogan, 2009; Meyer, 2003).

O preconceito tem sido estudado sob diversas perspectivas: uma frustração reprimida e deslocada para grupos mais fracos (Hovland
\& Sears, 1940); o desenvolvimento de um tipo de personalidade autoritária (Adorno, Frenkel-Brunswik, Levinson, \& Sanford, 1950); a pouca disposição à abertura mental (Rokeach, 1960); a falta de contatos com membros de grupos minoritários (Allport, 1954). Posteriormente, estas perspectivas individualizantes foram retomadas pelos teóricos da cognição social (Fiske \& Taylor, 1991; Markus \& Zajonc, 1985), os quais estudaram o preconceito como um erro no processamento das informações (Hewstone, 1990; Ross, 1977). Apesar das diferenças entre elas, a maior parte destas teorias enfatizam a origem psicológica e individual do preconceito. $\mathrm{O}$ aspecto social é também elemento fundamental no entendimento da dinâmica do pre- 
conceito. Os autores Prado e Machado (2008), dizem que:

O preconceito social pode ser entendido como um dos mecanismos da manutenção da hierarquização entre os grupos sociais e da legitimação da inferiorização social na história de uma sociedade, o que muitas vezes consolida-se como violência e ódio de uns sobre outros. (p. 67)

Prado e Machado (2008), dizem ainda que há um elemento paradoxal no preconceito, isso porque ele nos impede de "ver" que "não vemos" e "o que é que não vemos", ou seja, ele atua ocultando razões que justificam determinadas formas de inferiorizações históricas, naturalizadas por seus mecanismos.

Especificamente quanto ao preconceito homofóbico, durante a década de 60 , o termo homofobia já era empregado como sinônimo de atitudes e comportamentos ofensivos a gays e lésbicas (Cerqueira-Santos, Winter, Salles, Longo, \& Teodoro, 2007). Essa terminologia suscitou várias críticas, pois pressupõe que tais hostilidades derivam de algum tipo de medo irracional sentido por parte da maioria heterossexual, o que poderia ser compreendido a partir de um modelo de enfermidade e, portanto, passível de ser superado por via de tratamento, como ocorre com outras fobias (Herek, 2000). Dessa forma, o autor reforça a ideia de que a homofobia é muito mais uma forma de preconceito do que uma fobia qualquer. Neste estudo, assim como Cerqueira-Santos e colaboradores (2007), consideramos o fenômeno como uma forma de preconceito. Especificamente, analisam-se formas de preconceito que podem colocar a população de gays e lésbicas distantes de uma possibilidade e direito de construir uma família a partir da adoção de crianças.

\section{Adoção Homoparental}

A adoção homoparental é entendida como a modalidade de adoção na qual o casal adotante é constituído por homossexuais (Patterson, 2006) ou por apenas um indivíduo que se declara homossexual. Costa et al. (2013) realizaram levantamento no qual mostra a situação da adoção homoparental em diversos países. Segundo os autores há diferenças na legislação de cada país sobre a permissão para tal tipo de adoção; na Europa, por exemplo, Bélgica, Dinamarca, Islândia, Holanda, Noruega, Espanha, Suécia e Reino Unido permitem a adoção por dois homens ou duas mulheres, assim como por solteiros sem declarar a orientação sexual.

No Brasil, desde 2011 casais homoafetivos conseguiram o direito de ter oficialmente sua união civil, assim a adoção pelo casal passou a ser possível. Não há vedação legal para a instituição da adoção de crianças por casais homossexuais no país. Conforme o Estatuto da Criança e do Adolescente (ECA, 1990), não há a proibição de adoção por casais do mesmo sexo, sendo assim, a orientação sexual não deve ser critério de exclusão ou hierarquização de candidatos à adoção. Em abrangência jurídica o reconhecimento pela união homoafetiva trata-se puramente do reconhecimento de que houve um empenho coletivo com o interesse de unir patrimônios, e nada mais do que isso. No direito de família, quando se fala de união, refere-se que este é muito mais do que um esforço de unir patrimônio. É uma comunhão de vida, de existência, projetos de vida, intimidade, privacidade, projeto de felicidade pessoal (Rios, 2002). Tais avanços jurídicos podem também apontar para a busca de conformidade, num mecanismo de ajuste social. Conforme aponta Butler (2003), a busca de introdução à norma (inclusive norma jurídica) de minorias sexuais (neste caso a formação de uma família adotiva gay), pode se tratar de uma repetição subversiva.

Em estudo de revisão sistemática da literatura, Cecílio, Scorsolini-Comin e Santos (2013) apontam que no Brasil, em uma década (20002010) apenas dez estudos sobre a adoção homoparental foram realizados e publicados nas principais bases de dados científicas do país; sendo três artigos empíricos e sete teóricos. Os autores destacam especialmente três tendências nos estudos sobre a temática: a preocupação com as consequências da adoção para as crianças (aspectos desenvolvimentais negativos e positivos); as alternativas na busca da parentalidade; e, as questões ligadas à adoção em si (legislação, mudanças históricas etc). 
Em estudo semelhante, Araújo e colaboradores (2007), identificaram que $51 \%$ dos estudantes universitários de Direito e de Psicologia são contrários à adoção por casais homossexuais. Segundo tal estudo, os universitários contrários alegam justamente a melhor decisão para as crianças, ancorados em noções negativas sobre como um casal homossexual poderia educar seus filhos. $\mathrm{O}$ argumento principal seria a carência de referencial de ambos os sexos para o desenvolvimento saudável da criança. Curiosamente, estudantes de Psicologia demonstraram tal opinião, provavelmente amparados em modelos psicológicos clássicos e pouco críticos frente às novas formas de parentalidade.

Em estudo recente, Baiocco e Fiorenzo (2013) mostraram que gays e lésbicas justificam uma menor vontade de ter filhos pensando nos problemas que vão enfrentar, como o preconceito e a falta de suporte de pessoas próximas e instituições. Uma das consequências desta falta de perspectiva positiva é a desistência da ideia de adoção por medo de falhas no processo de parentalidade. De forma semelhante Pacilli, Taurino, Jost e van der Toorn (2011) encontraram uma avaliação negativa de práticas parentais de gays e lésbicas em grupos de alta exibição de homofobia. Tal avaliação ultrapassa o grupo majoritário e é introjetada pelo próprio grupo não-heterosexual.

Como ressaltado por Campos e Costa (2004), os aspectos subjetivos estão presentes nos estudos psicossociais de adoção. Tal pesquisa mostra que a opinião de profissionais muitas vezes ultrapassa a técnica ou variáveis racionais na elaboração de pareceres, gerando dúvidas, medos e confusões entre profissionais e adotantes. Neste sentido, o Conselho Federal de Psicologia (CFP) publicou, em 2008, uma "cartilha", que orienta psicólogos do judiciário na atuação em varas de adoção no sentido de diminuir possíveis atuações enviesadas de alguns profissionais. No campo de Direito e do Serviço Social, Silva e Tavares (2007) destacam que poucos avanços são percebidos e relatados sobre práticas profissionais, talvez ainda pela desatualização na formação de graduação nestas áreas sobre questões de desenvolvimento humano e sexualidade.
O presente estudo teve como objetivo investigar as crenças de estudantes de Direito e Serviço Social sobre orientação sexual e adoção homoaparental, descrevendo e comparando grupos. Como objetivos específicos, buscou-se identificar a relação do contato interpessoal e amizade com homossexuais no que diz respeito ao processo da adoção homoparental. Justifica-se a escolha dos estudantes destas áreas pelo fato de que muitos serão agentes de fundamental importância na operacionalização dos direitos na forma de adoção. Profissionais de Psicologia, que também podem fazer parte deste processo, foram excluídos do estudo por terem em sua formação conteúdos específicos sobre desenvolvimento humano e sexualidade, podendo dar respostas esperadas.

\section{Método}

\section{Participantes}

Participaram da pesquisa 132 universitários de ambos os sexos, sendo $67(49,2 \%)$ do curso de Serviço Social e 65 (50,8\%) do curso de Direito. Todos os estudantes de Direito e de Serviço Social a partir do sexto semestre de uma Universidade pública foram convidados a participar do estudo. A amostra alcançada teve idade variando entre 19 e 43 anos, com uma média de 25,70 anos $(D P=5,51)$. Não foram encontradas diferenças significativas entre os cursos para as principais variáveis demográficas, como renda, idade, procedência escolar e autodeclaração de orientação sexual. O curso de Serviço Social tem maior número de mulheres matriculadas.

\section{Instrumento}

Foram aplicados questionários estruturados com os participantes do estudo, sendo que junto ao questionário foi apresentado o TCLE (Termo de Consentimento Livre e Esclarecido). O questionário era constituído por questões sóciodemográficas e por duas escalas. Uma a respeito de crenças sobre a homossexualidade, contendo 29 afirmações (Cerqueira-Santos et al., 2007); e outra escala que diz respeito a crença sobre a adoção homoparental, contendo no total 18 afirmações extraídas de Falcão (2004). Nas duas 
escalas os estudantes indicaram o grau de concordância com cada um dos itens que varia de 1 (discordo totalmente) a 5 (concordo totalmente). Além disso, questionou-se sobre o contato e informação sobre homossexualidade (amigos homossexuais e informações acadêmicas sobre sexualidade humana). A escala de crenças sobre homossexualidade obteve dois fatores (crenças positivas com alfa de 0,86 ; e crenças negativas, com alfa de 0,78$)$. A escala de crenças sobre a adoção homossexual também apresentou dois fatores, um de crenças positivas e outro de crenças negativas, com alfas respectivos de $0,76 \mathrm{e}$ 0,83 .

\section{Procedimento}

Os participantes foram convidados em sala de aula para que completassem os questionários. Primeiramente foi apresentado o termo de consentimento livre e esclarecido, onde eram explanados todos os objetivos da pesquisa, além de frisar o sigilo das informações prestadas e o uso exclusivo para fins acadêmicos. Aos entrevistados, foram garantidos o sigilo e anonimato das informações contidas nas respostas dos questionários. Os questionários foram entregues de maneira coletiva deixando claro que os universitários poderiam levar o tempo que precisassem para responder. O tempo médio da aplicação coletiva por turma foi de aproximadamente 10 minutos. Não houve recusas ou reação negativa ao estudo. Todos devolveram em envelope único para evitar qualquer identificação.

\section{Análise de Dados}

Os dados foram tabulados no programa estatístico SPSS 16.0 for Windows. Foram realizados: análise fatorial das escalas utilizadas para confirmação do modelo original e da consistência interna dos fatores (conforme alfas descritos acima); análise descritiva da amostra; análises de teste $t$ de Student comparando os grupos por cursos investigados; e, análise de correlação entre as variáveis do estudo. Para as análises descritivas de concordância e discordância, foram agrupados as respostas de maneira binária concordo $\mathrm{x}$ discordo.

\section{Questões Éticas}

Os aspectos éticos que garantem a integridade dos participantes deste estudo foram assegurados, com base na Resolução $n^{\circ}$ 466/2012 que consiste em diretrizes e normas que regulam as pesquisas com os seres humanos (Conselho Nacional de Saúde, 2013) e na Resolução No 016 do CFP (2000). Além do Termo de Consentimento Livre e Esclarecido, foi garantido o sigilo das informações pessoais, assim como disponibilizada a assistência do membro da equipe de pesquisa, caso algum participante necessite de apoio psicológico provocado pela lembrança negativa de algum dos aspectos investigados. O projeto foi encaminhado e aprovado pelo Comitê de Ética em Pesquisa envolvendo Seres Humanos da Universidade onde o estudo foi realizado.

\section{Resultados}

Este estudo contou com um total de 132 participantes, sendo 67 (49,2\%) do curso de Serviço Social e $65(50,8 \%)$ do curso de Direito, com uma média geral de 25,70 anos de idade $(D P=5,51)$ entre os estudantes de ambos os cursos. Todos os participantes frequentavam universidade federal pública, e cursavam entre o $6^{\circ}$ e $9^{\circ}$ período de seus respectivos cursos.

No que se refere às variáveis sociodemográficas, nota-se na que houve uma predominância no estado civil de solteiros, o que já era esperado, uma vez que os universitários deste curso são mais jovens. Na variável "filhos" nota-se que menos de $30 \%$ da amostra já tem filhos. No que diz respeito ao afeto sentido por outras pessoas ambos os cursos se sobressaíram como "exclusivamente heterossexual", sendo a frequência dos dois cursos iguais -48 . No que se refere à auto identificação da orientação sexual dos participantes da pesquisa, no curso de Direito encontram-se $51(78,5 \%)$ heterossexuais, $9(13,8 \%)$ homossexuais, $4(6,2 \%)$ bissexuais e $1(1,5 \%)$ que se declarou pertencendo a outra orientação sexual. Já no curso de Serviço Social encontram-se $55(82,1 \%)$ heterossexuais, $8(11,9 \%)$ homossexuais, $2(3 \%)$ bissexuais e $2(3 \%)$ que se afirmaram em "outros" (sem orientação defini- 
da). É interessante notar que o número de pessoas que declaram o afeto e a orientação sexual não é o mesmo, ou seja, há certa divergência para alguns participantes quanto seu afeto e sua auto identificação com grupos de orientação sexual. Quanto ao contato com pessoas de orientação homossexual apenas $1(1,5 \%)$ pessoa tanto no curso de Direito quanto de Serviço Social falou que não tem nenhum contato com homossexuais. Sobressaiu-se nesta questão o "contato mo- derado" com uma frequência de 54 (52,3\%) em Direito e 26 (38,8\%) em Serviço Social. No que diz respeito à quantidade de amigos todos os participantes da pesquisa declararam ter ao menos 1 amigo homossexual, sendo que em Direito a maioria das respostas se situaram em 1-2 amigos com 31 (47,7\%) das respostas; e em Serviço Social a maioria das respostas se situaram em 5 ou mais amigos com $25(37,3 \%)$ das respostas do curso (ver Tabela 1).

Tabela 1

Afeto, Orientação Sexual e Contato com Homossexuais por Curso

\begin{tabular}{|c|c|c|c|c|c|c|}
\hline \multirow[t]{2}{*}{ Variáveis } & \multicolumn{2}{|c|}{ Direito } & \multicolumn{2}{|c|}{ Serviço Social } & \multicolumn{2}{|c|}{ Total } \\
\hline & $n$ & $\%$ & $n$ & $\%$ & $n$ & $\%$ \\
\hline \multicolumn{7}{|l|}{ Afeto } \\
\hline Exclusivamente heterossexual & 48 & $73,8 \%$ & 48 & $71,6 \%$ & 96 & $72,7 \%$ \\
\hline Heterossexual & 4 & $6,2 \%$ & 8 & $11,9 \%$ & 12 & $9,1 \%$ \\
\hline Bissexual & 3 & $4,6 \%$ & 4 & $6 \%$ & 7 & $5,3 \%$ \\
\hline Homossexual & 3 & $4,6 \%$ & 6 & $9 \%$ & 9 & $6,8 \%$ \\
\hline \multicolumn{7}{|l|}{ Orientação Sexual } \\
\hline Heterossexual & 51 & $78,5 \%$ & 55 & $82,1 \%$ & 106 & $80,3 \%$ \\
\hline Homossexual & 9 & $13,8 \%$ & 8 & $11,9 \%$ & 17 & $12,9 \%$ \\
\hline Bissexual & 4 & $6,2 \%$ & 2 & $3 \%$ & 6 & $4,5 \%$ \\
\hline \multicolumn{7}{|l|}{ Contato } \\
\hline Nenhum contato & 1 & $1,5 \%$ & 1 & $1,5 \%$ & 2 & $1,5 \%$ \\
\hline Pouco contato & 16 & $24,6 \%$ & 17 & $25,4 \%$ & 33 & $25,0 \%$ \\
\hline Contato moderado & 54 & $52,3 \%$ & 26 & $38,8 \%$ & 60 & $45,5 \%$ \\
\hline \multicolumn{7}{|l|}{ Amigos homossexuais } \\
\hline Nenhum amigo & 0 & $0 \%$ & 0 & $0 \%$ & 0 & $0 \%$ \\
\hline 1-2 amigos & 31 & $47,7 \%$ & 20 & $29,9 \%$ & 51 & $38,6 \%$ \\
\hline 3-4 amigos & 20 & $30,8 \%$ & 22 & $32,8 \%$ & 42 & $31,8 \%$ \\
\hline 5 ou mais amigos & 14 & $21,5 \%$ & 25 & $37,3 \%$ & 39 & $29,5 \%$ \\
\hline
\end{tabular}

Com relação às crenças negativas sobre a homossexualidade (Tabela 2) as questões que mais se destacaram foram "Homossexuais são mais promíscuos do que heterossexuais". Percebe-se que a resposta que se sobressaiu foi "Discordo", tanto no curso de Direito - 33 (50,8\%) como em Serviço Social - 38 (56,7\%), sendo que nesta mesma questão ninguém respondeu
"Concordo". Quando questionados sobre os homossexuais usarem mais drogas e se exporem mais a doenças sexualmente transmissíveis (DST's) a maioria dos universitários dos dois cursos falaram que concordam com tal afirmação. O mesmo ocorre na questão da religião e homossexualidade; a maioria dos estudantes concorda que os homossexuais se afastam mais 
da religião por causa da sua orientação sexual. Com relação ao uso de drogas, no curso de Direito encontramos em "Discordo" - 42 (50,8\%), "Concordo" - 21 (32,3\%) e em Serviço Social "Discordo"- 57 (85,1\%) e "Concordo"- 4 (6\%).

De maneira geral percebe-se algumas diferenças entre Direito e Serviço Social. Por exem- plo, os alunos de Serviço Social concordam mais que homossexuais são mais promíscuos e que eles se expõem mais a AIDS e DST. Já os estudantes do curso de Direito concordam mais que os homossexuais usam mais drogas, são menos fiéis, se afastam da religião e que seus relacionamentos são menos duradouros.

Tabela 2

Frequência e Percentual de Concordância com Crenças Negativas sobre Homossexualidade

\begin{tabular}{lcccccc}
\hline \multicolumn{1}{c}{ Variáveis } & \multicolumn{2}{c}{ Direito } & \multicolumn{2}{c}{ Serviço Social } & \multicolumn{2}{c}{ Total } \\
& $n$ & $\%$ & $n$ & $\%$ & $n$ & $\%$ \\
\hline Homossexuais são mais promíscuos do que hetero. & 0 & $0 \%$ & 4 & $6 \%$ & 4 & $3 \%$ \\
Homossexuais usam mais drogas do que hetero. & 21 & $32,3 \%$ & 4 & $6 \%$ & 25 & $19,0 \%$ \\
Relacionamentos Homossexuais são menos duradouros. & 22 & $33,8 \%$ & 13 & $19,4 \%$ & 35 & $26,5 \%$ \\
Homossexuais são menos fiéis do que hetero. & 23 & $36,5 \%$ & 17 & $25,8 \%$ & 40 & $31,0 \%$ \\
Homossexuais se expõem mais a DST's e AIDS. & 35 & $53,9 \%$ & 42 & $63,6 \%$ & 77 & $58,8 \%$ \\
Homossexuais se afastam da religião. & 43 & $67,2 \%$ & 38 & $57,6 \%$ & 81 & $62,3 \%$ \\
\hline
\end{tabular}

Com relação às crenças positivas que dizem respeito à homossexualidade (Tabela 3), nas respostas dos universitários pode-se observar que $82,8 \%$ dos alunos de Direito acham que os homossexuais se esforçam mais para serem bem sucedidos, já no curso de Serviço Social $84,1 \%$ concordam com essa afirmação. Quando perguntados a respeito dos homossexuais serem mais divertidos e criativos, nenhum participante afirmou discordar totalmente dessa afirmação. As respostas do curso de Direito se firmaram mais na opção "concordo" sendo 59 (92,2\%) e no curso de Serviço Social a maioria marcou a opção "concordo" com uma frequência de 61 $(91,1 \%)$. Já na afirmação "Homossexuais são mais sensíveis", no curso de Direito encontramos em "concordo" uma frequência de $46(70,7 \%)$ e em Serviço Social - "concordo" frequência de $49(73,2 \%)$.

Tabela 3

Frequência e Percentual de Concordância Crenças Positivas sobre Homossexualidade

\begin{tabular}{lcrrrrr}
\hline \multicolumn{1}{c}{ Variáveis } & \multicolumn{2}{c}{ Direito } & \multicolumn{2}{c}{ Serviço Social } & \multicolumn{2}{c}{ Total } \\
& $\mathrm{n}$ & $\%$ & $\mathrm{n}$ & $\%$ & $\mathrm{n}$ & $\%$ \\
\hline Homossexuais se esforçam mais para serem bem sucedidos. & 53 & $82,8 \%$ & 53 & $84,1 \%$ & 106 & $83,5 \%$ \\
Homossexuais são mais criativos e divertidos. & 59 & $92,2 \%$ & 61 & $91,1 \%$ & 120 & $91,6 \%$ \\
Homossexuais são mais sensíveis. & 46 & $70,7 \%$ & 49 & $73,2 \%$ & 95 & $72,0 \%$ \\
\hline
\end{tabular}

Numa segunda etapa do instrumento, foram investigadas as crenças sobre a adoção homoafetiva. A Tabela 4 descreve a escala sobre as crenças negativas da adoção homoafetiva. Nesta escala os universitários do curso de Direito pontuaram mais na concordância para os itens: "serão homossexuais no futuro"; "desenvolverá comportamentos diferentes das criadas por heterossexuais"; e, "terá comportamentos homossexuais desde pequena". Quando questionados 
sobre o fato de que as crianças criadas por homossexuais seriam desajustadas $10,7 \%$ dos estudantes de Direito concordaram com essa afirmação e nenhum estudante de Serviço Social concordou com tal afirmação. Quando questionados se uma criança criada por homossexuais também será homossexual no futuro, $32,3 \%$ dos estudantes de Direito e 4,5\% de Serviço Social concordaram com essa afirmação. Assim como nos questionamentos acima, quando perguntados se as crianças criadas por homossexuais serão diferentes das criadas por heterossexuais, $28,1 \%$ de Direito concordam e $11,9 \%$ de Serviço Social também concordam com tal afirmação. Os estudantes do curso de Direito também concordam mais que a criança adotada por homossexuais aprenderá seus costumes e terá comportamentos homossexuais e que crianças criadas por homossexuais poderão ser abusadas pelos pais adotivos. Nesta parte da escala o que mais chamou atenção foi o fato de nenhum participante achar que um casal homossexual não ensinará para uma criança os valores que a sociedade exige.

Tabela 4

Frequência e Percentual de Concordância Crenças Negativas a Respeito da Adoção por Homossexuais

\begin{tabular}{|c|c|c|c|c|c|c|}
\hline & \multicolumn{2}{|c|}{ Direito } & \multicolumn{2}{|c|}{ Serviço Social } & \multicolumn{2}{|c|}{ Total } \\
\hline & $n$ & $\%$ & $n$ & $\%$ & $n$ & $\%$ \\
\hline As crianças adotadas por homossexuais serão desajustadas. & 7 & $10,7 \%$ & 0 & $0 \%$ & 7 & $5,3 \%$ \\
\hline $\begin{array}{l}\text { Uma criança adotada por um casal homossexual aprenderá } \\
\text { essa imagem de família e se tornará homossexual no futuro. }\end{array}$ & 21 & $32,3 \%$ & 3 & $4,5 \%$ & 24 & $18,3 \%$ \\
\hline $\begin{array}{l}\text { Um casal homossexual não ensinará para uma criança } \\
\text { os valores morais que a sociedade exige. }\end{array}$ & 0 & $0 \%$ & 0 & $0 \%$ & 0 & $0 \%$ \\
\hline $\begin{array}{l}\text { O problema de uma criança adotada por homossexuais } \\
\text { é que outras crianças a humilharão. }\end{array}$ & 42 & $64,6 \%$ & 27 & $55,2 \%$ & 79 & $59,9 \%$ \\
\hline $\begin{array}{l}\text { Os filhos aprendem observando os pais e uma criança } \\
\text { educada por homossexuais irá desenvolver comportamentos } \\
\text { diferentes das criadas por heterossexuais. }\end{array}$ & 18 & $28,1 \%$ & 8 & $11,9 \%$ & 26 & $19,9 \%$ \\
\hline $\begin{array}{l}\text { Uma criança adotada por homossexuais aprenderá } \\
\text { que a homossexualidade é algo natural e terá } \\
\text { comportamentos homo desde pequena. }\end{array}$ & 26 & $40,0 \%$ & 11 & $16,4 \%$ & 37 & $28,1 \%$ \\
\hline $\begin{array}{l}\text { Uma criança adotada por gays ou lésbicas poderá } \\
\text { ser abusada sexualmente por eles. }\end{array}$ & 9 & $13,8 \%$ & 3 & $4,5 \%$ & 12 & $9,1 \%$ \\
\hline
\end{tabular}

A Tabela 5 descreve as crenças positivas sobre a adoção por pessoas homossexuais. Destaca-se que para a maioria dos itens, há mais respostas positivas para o curso de Serviço Social (ser criada por homossexuais não influenciará no desenvolvimento da criança $-72,3 \%$; a criança se desenvolverá normalmente $-85,1 \%$; o amor é mais importante que a orientação dos pais $92,4 \%$; serão tão ajustadas como crianças criadas por heterossexuais $-67,6 \%$; homossexuais podem oferecer lares dignos para as crianças $89,6 \%$ ). Sendo que apenas em três itens Serviço Social e Direito são semelhantes em suas respostas (num lar onde há diálogo, a criança adotada não guardará traumas de infầncia - 72,3\% estudantes de Direito concordam e $70,1 \%$ de Serviço Social; uma criança criada por homossexuais será um adulto adaptado socialmente - 76,9\% dos estudantes de Direito e $89,5 \%$ de Serviço Social; uma criança educada com valores morais numa família homossexual será um adulto normal - 76,9\% de Direito e $95,5 \%$ de Serviço Social). Dessa forma, percebe-se que os estudantes do curso de Serviço Social têm opiniões mais favoráveis quando comparados com o curso de Direito, o que já era esperado já que os estudantes do curso de Serviço Social também apresentaram escores menores na escala de crenças negativas sobre a homossexualidade e sobre a adoção. 
Tabela 5

Frequência e Percentual de Concordância Crenças Positivas a Respeito da Adoção por Homossexuais

\begin{tabular}{|c|c|c|c|c|c|c|}
\hline & \multicolumn{2}{|c|}{ Direito } & \multicolumn{2}{|c|}{ Serviço Social } & \multicolumn{2}{|c|}{ Total } \\
\hline & $n$ & $\%$ & $n$ & $\%$ & $n$ & $\%$ \\
\hline $\begin{array}{l}\text { Se uma criança recebe amor e atenção, o fato de ser criada } \\
\text { por homossexuais não influenciará seu desenvolvimento. }\end{array}$ & 30 & $46,1 \%$ & 47 & $72,3 \%$ & 77 & $59,2 \%$ \\
\hline $\begin{array}{l}\text { Uma criança adotada por homossexuais irá desenvolver a } \\
\text { capacidade de aceitar sua família e se desenvolver normalmente. }\end{array}$ & 24 & $36,9 \%$ & 57 & $85,1 \%$ & 81 & $61,4 \%$ \\
\hline $\begin{array}{l}\text { Na criação de filhos o amor é mais importante que } \\
\text { a orientação sexual dos pais. }\end{array}$ & 55 & $84,6 \%$ & 61 & $92,4 \%$ & 116 & $88,6 \%$ \\
\hline $\begin{array}{l}\text { Se o casal homossexual é formado por duas pessoas ajustadas, } \\
\text { a criança irá se desenvolver normalmente. }\end{array}$ & 41 & $63,1 \%$ & 53 & $82,9 \%$ & 94 & $72,9 \%$ \\
\hline $\begin{array}{l}\text { Uma criança pode ser adotada por homossexuais } \\
\text { e não apresentar comportamentos homossexuais. }\end{array}$ & 33 & $50,8 \%$ & 49 & $73,1 \%$ & 82 & $62,1 \%$ \\
\hline $\begin{array}{l}\text { As crianças criadas por homossexuais são tão ajustadas } \\
\text { como as criadas por heterossexuais. }\end{array}$ & 34 & $52,3 \%$ & 44 & $67,6 \%$ & 78 & $60,0 \%$ \\
\hline $\begin{array}{l}\text { Num lar composto por homossexuais onde existe muito dialogo, } \\
\text { a criança adotada não guardará traumas da infância. }\end{array}$ & 47 & $72,3 \%$ & 47 & $70,1 \%$ & 94 & $71,3 \%$ \\
\hline $\begin{array}{l}\text { Uma criança educada com os valores morais numa família } \\
\text { homossexual será um adulto adaptado socialmente. }\end{array}$ & 50 & $76,9 \%$ & 60 & $89,5 \%$ & 110 & $83,3 \%$ \\
\hline $\begin{array}{l}\text { Casais homossexuais têm condições emocionais de oferecerem } \\
\text { lares dignos para crianças. }\end{array}$ & 28 & $44,4 \%$ & 60 & $89,6 \%$ & 88 & $67,7 \%$ \\
\hline $\begin{array}{l}\text { Os estímulos oferecidos para uma criança se desenvolver num } \\
\text { lar composto por homo são iguais de um lar formado por heteros. }\end{array}$ & 15 & $23,1 \%$ & 34 & $50,7 \%$ & 49 & $37,2 \%$ \\
\hline $\begin{array}{l}\text { Uma criança educada com valores morais numa família } \\
\text { homossexual será um adulto normal. }\end{array}$ & 50 & $76,9 \%$ & 63 & $95,5 \%$ & 113 & $86,3 \%$ \\
\hline
\end{tabular}

Foram realizados cálculos para compor os índices das duas escalas utilizadas. Para cada escala foi feito um somatório das respostas e médias para cada curso como indicadores da concordância sobre a adoção homoparental e do preconceito contra homossexuais. Para cada escala os itens foram ajustados com direção única na formação do índex somatório. Foi calculado teste $t$ comparando as médias de Direito e Serviço Social em cada escala. A partir de então pode- -se observar que há diferenças significativas entre os cursos nas duas escalas. A Tabela 6 mostra os resultados comparando a concordância, em uma escala que variava de 54 a 77, para adoção e 15 e 28, para preconceito homossexual. A concordância da adoção encontrada em estudantes de direito foi de 61,01 enquanto serviço social obteve $68,87(t=12,27 ; p<0,001)$. Na escala de preconceito homossexual, os estudantes de direito obtiveram 22,80 e os estudantes de serviço social obtiveram 21,65 $(t=2,03 ; p=0,045)$.

Tabela 6

Tabela de Teste t Comparando Direito e Serviço Social quanto à Concordância para Adoção Homossexual e Preconceito Homossexual

\begin{tabular}{lcccc}
\hline & Direito & Serviço Social & $t$ & $p$ \\
\hline Índice de concordância para adoção homoparental & 61,01 & 68,87 & 12,27 & $<0,001$ \\
Índice de preconceito homossexual & 22,80 & 21,65 & 2,03 & 0,045 \\
\hline
\end{tabular}


Por fim, foi realizada uma análise de correlação para cada curso investigado, inserindo as variáveis de interesse: índice de concordância para a adoção homoparental, índice de preconceito, contato interpessoal com pessoas homossexuais e número de amigos homossexuais. Os resultados foram semelhantes paras os dois cursos e conforme o esperado, sendo a correlação significativa $(r=-0,25 ; p>0,005)$ e negativa entre a concordância para a adoção e o preconceito; e positiva $(r=0,20 ; p>0,05)$ entre concordância para a adoção e contato interpessoal, assim como número de amigos homossexuais.

\section{Discussão}

A partir de 2009 com a promulgação da nova lei da adoção (Lei $N^{\circ} 12.010$ ), crianças e adolescentes passam a ter a possibilidade de serem adotadas por casais homoafetivos. No entanto, tal prática tem gerado discussões e polêmicas por estar sendo aplicada de maneira pouco consistente, o que pode supor a falta de informação e preconceito por parte de diversos atores (profissionais, casais, sociedade civil, autoridades). Apesar de alguns autores tentarem encarar a homoparentalidade como uma nova forma de organização familiar, Fonseca (2008) destaca que este fenômeno vai além disso, questionando as categorias básicas de parentesco. Fonseca também considera a ideia negativa da adoção na cultura brasileira, mesmo entre casais heterossexuais. Dessa forma, entende-se que está em jogo não apenas velhas crenças, mas práticas normalizadas e engessadas que devem ser revistas. Profissionais de Direito e Serviço social são atores fundamentais na implementação dessas novas práticas, no entanto, parecem carecer de informações sobre desenvolvimento e sexualidade humana no processo da tomada de decisão. Fonseca (2008) lembra que existe um caráter contratual na noção de família. Ou seja, além dos vínculos afetivos (biológicos ou não) essa relação é de certa forma regulada pelo Estado e por leis que definem certos papéis. Neste sentido, o direito deve ser claro e a luta pela não discriminação de famílias homoparentais toma outro sentido, que passa do prático para o simbólico e vice-versa.
Como apontam Cecílio et al. (2013), a visibilidade das famílias homoparentais como um contexto possível e não-tradicional tem forçado que se pense as relações de parentesco de diferentes perspectivas. O Direito tem sido uma das áreas mais cobradas por avanços que acompanhem tais reconfigurações. Assim como em outros países, no Brasil, as mudanças são verdadeiros palcos de batalhas entre posturas conservadoras e um luta pela cidadania plena de quem vive situações de quase marginalidade. Cecílio et al. (2013) destacam que:

as dificuldades legais para o reconhecimento dessas famílias, bem como a discriminação e o preconceito que envolvem não apenas o casal homoafetivo, como também a criança adotada, acabam por repercutir no modo como essas famílias têm se estruturado e se reconhecido em termos de sua identidade. (p. 511)

Os dados destacados neste estudo ilustram uma realidade pouco positiva no cenário da formação de profissionais que poderão atuar na área de adoção. De maneira geral, os dados mostram ainda uma rejeição à ideia de adoção homoparental e crenças negativas sobre a homossexualidade. Sugerindo uma correlação entre estas duas posições para estudantes universitários de Direito e de Serviço Social. Tais dados corroboram estudos anteriores sobre a temática, como de Falcão (2004) que já apontava o fato de que universitários acreditam em sua maioria que a homossexualidade é um desvio de valores e discordam da adoção. Quadro semelhante também foi encontrado por Araújo e colaboradores (2007) e Lacerda, Pereira e Camino (2002). Existem limitações claras para a interpretação dos dados deste estudo, uma vez que o caráter linear das escalas foi achatado pela análise binária de concordância ou discordância nas comparações de médias. No entanto, apesar de não identificar como forma de preconceito, os diferentes níveis de concordância com sentenças negativas parecem ser um bom indicador de crenças ainda enraizadas, especialmente para a amostra de universitários.

Era a principal hipótese deste estudo, que os estudantes de Direito seriam mais contrários à adoção de crianças do que os estudantes do cur- 
so de Serviço Social, devido à lei brasileira ter demorado tanto tempo para "permitir" a adoção por homossexuais. Além do que, na pesquisa de Figueirêdo (2003) os profissionais do direito foram o que menos aceitaram a adoção pelo casal homossexual. Nos resultados desta pesquisa foram constatados que realmente, os universitários do curso de direito apresentam um índice maior de crenças negativas contra homossexuais e contra a adoção assistida por eles, quando comparados aos estudantes de serviço social. De forma semelhante, o estudo de Araújo e colaboradores (2007) já mostrou a grande rejeição por parte dos estudantes de direito e a justificativa a partir do argumento sobre prejuízos para a criança adotada. Além dos argumentos de cunho "psicológico", este estudo percebe também argumentos "morais" contra homossexuais em geral e negando o direito à adoção, mais uma vez, especialmente entre estudantes de Direito.

Outro aspecto de destaque neste estudo é o resultado sobre a correlação entre contato interpessoal, amizades e crenças sobre a homossexualidade e concordância com a adoção homoparental. Os resultados corroboram o que já havia sido relatado por Cerqueira-Santos e colaboradores (2007) demonstrando o efeito do contato na quebra de preconceitos, além de sugerir a maior informação sobre o tema da sexualidade na formação de universitários em geral. Tais resultados nos remetem à sugestão feita por Crawford, McLeod, Zamboni e Jordan (1999), na qual indicam que a homossexualidade deve ser estudada no curso de graduação e pós-graduação, no intuito de desmistificar certos conceitos sobre a homossexualidade, pois as pessoas representam no senso comum teorias científicas enviesadas e mal interpretadas.

Ainda sobre a importância do debate dentro da academia, Mott (2003) relata que muitos docentes divulgam opiniões negativas em relação à homossexualidade e pesquisadores não são estimulados e são até barrados a investigar temas relacionados à sexualidade humana. Existe uma barreira de silêncio na sociedade em geral, nas escolas e universidades, como se os temas não tivessem importância nos meios culturais. Defende-se que o debate sobre a sexualidade humana deva acontecer em escolas do ensino fundamental e médio e estendida a todos os cursos das universidades, principalmente da área de Ciências Humanas, no intuito de haver um maior preparo dos futuros profissionais e uma maior tolerância e respeito à orientação sexual de cada individuo.

\section{Considerações}

Este estudo demonstrou que a questão da adoção homoparental ainda está distante da realidade de profissionais em formação em áreas tão próximas à temática. Os dados empíricos deste estudo possuem limitações do ponto de vista estatístico que impedem análises mais robustas, no entanto, exemplificam uma realidade e disparam uma série de discussões que podem ser úteis no repensar a formação para novas realidades. Permanece explícita a hegemonia do arranjo heterossexista na representação de família e crenças sobre desenvolvimento humano (Butler, 2003). "A repetição de construtos heterossexuais nas culturas sexuais gay e hetero bem pode representar o lugar inevitável da desnaturalização e mobilização das categorias de gênero" (Butler, 2003, pp. 56-57).

Ilustra-se aqui como crenças enviesadas e mal interpretadas colaboram na construção de um julgamento pouco justo e distante das realidades e dos avanços no campo social e político. Sugere-se de forma parcimoniosa que os resultados desta pesquisa colaborem para a formulação de táticas na implementação de políticas públicas para os homossexuais, de modo a prover subsídios na alteração dos estereótipos negativos e preconceitos relacionados aos pares homoafetivos, de modo que haja respeito e tolerância à diversidade da orientação sexual na sociedade.

\section{Referências}

Adorno, T. W., Frenkel-Brunswik, E., Levinson, D. J., \& Sanford, R. N. (1950). The authoritarian personality. London: Harpers.

Allport, G. (1954). The nature of prejudice. Reading, MA: Addison-Wesley

Araújo, L. F., Oliveira, J. S. C., Sousa, V. C., \& Castanha, A. R. (2007). Adoção de crianças por 
casais homoafetivos: Um estudo comparativo entre universitários de Direito e de Psicologia. Psicologia \& Sociedade, 19(2), 95-102. doi:10.1590/S0102-71822007000200013

Baiocco, R., D’Alessio, M., \& Laghi, F. (2010). Binge drinking among gay, and lesbian youths: The role of internalized homophobia, self-disclosure, and connectedness to the gay community. Addictive Behaviors, 35(10), 896899. doi:10.1016/j.addbeh.2010.06.004

Baiocco, R., \& Fiorenzo, L. (2013). Sexual orientation and the desires and intentions to become parents. Journal of Family Studies, 19(1), 90112. doi:10.5172/jfs.2013.19.1.90

Butler, J. (2003). Problemas de gênero. Feminismo e subversão da identidade. Rio de Janeiro, RJ: Civilização Brasileira.

Campos, N. M. V., \& Costa, L. F. (2004). A subjetividade presente no estudo psicossocial da adoção. Psicologia: Reflexão \& Critica, 17(1), 95-104. doi:10.1590/S0102-79722004000100012

Cecílio, M. S., Scorsolini-Comin, F., \& Santos, M. A. (2013). Produção científica sobre adoção por casais homossexuais no contexto brasileiro. Estudos de Psicologia (Natal), 18(3), 507-516. doi:10.1590/S1413-294X2013000300011

Cerqueira-Santos, E., Winter, F. S., Salles, L. A., Longo, J. L., \& Teodoro, M. L. M. (2007). Contato interpessoal e crenças sobre homossexualidade: Desenvolvimento de uma escala. Interação em Psicologia, 11(2), 221-229.

Conselho Federal de Psicologia. (2000). Resolução CFP $N^{\circ}$ 016/2000, de 20 de dezembro de 2000. Recuperada em http://site.cfp.org.br/wp-content/uploads/2000/12/resolucao2000 16.pdf

Conselho Federal de Psicologia. (2008). Adoção: Um direito de todos e todas. Brasília, DF: Autor.

Conselho Nacional de Saúde. (2013, 13 jun.). Resolução No 466, de 12 de dezembro de 2012. Diário Oficial da União, 12, Seção 1, p. 59 Recuperado em http://conselho.saude.gov.br/resolucoes/2012/Reso466.pdf

Costa, P. A., Caldeira, S., Fernandes, I., Rita, C., Pereira, H., \& Leal, I. (2013). Atitudes da população portuguesa em relação à homoparentalidade. Psicologia: Reflexão e Crítica, 26(4), 790798. doi:10.1590/S0102-79722013000400020

Crawford, I., McLeod, A., Zamboni, B. D., \& Jordan, M. B. (1999). Psychologists' attitudes to- ward gay and lesbian parenting. Professional Psychology: Research and Practice, 30(4), 394401. doi:10.1037/0735-7028.30.4.394

Estatuto da Criança e do Adolescente. (1990, 27 set.). Lei $\mathrm{N}^{\circ} 8.069$, de 13 de julho de 1990. Diário Oficial da União. Recuperado em http://www. planalto.gov.br/ccivil_03/LEIS/L8069.htm

Falcão, L. C. (2004). Adoção de crianças por homossexuais: Crenças e formas de preconceito (Dissertação de mestrado, Universidade Católica de Goiás, Goiânia, GO, Brasil).

Figueirêdo, L. C. B. (2003). Adoção para homossexuais. Curitiba, PR: Juruá.

Fiske, S. T., \& Taylor, S. E. (1991). Social cognition. New York: McGraw-Hill.

Fonseca, C. (2008). Homoparentalidade: Novas luzes sobre o parentesco. Revista Estudos Feministas, 16(3), 769-783. doi:10.1590/S0104-026X2 008000300003

Freire, L., \& Cardinali, D. (2012). O ódio atrás das grades: Da construção social da discriminação por orientação sexual à criminalização da homofobia. Sexualidad, Salud y Sociedad (Rio de Janeiro), (12), 37-63. Recuperado em http://www.scielo. br/scielo.php?script $=$ sci_arttext\&pid=S1984$-64872012000600003 \& \operatorname{lng}=p t \& t \operatorname{lng}=p t$. $10.1590 /$ S1984-64872012000600003

Herek, G. M. (2000). Sexual prejudice and gender: Do heterosexuals' attitudes toward lesbians and gay men differ? Journal of Social Issues, 56(2), 251-266.

Herek, G. M., Gillis, J. R., \& Cogan, J. C. (2009). Internalized stigma among sexual minority adults: Insights from a social psychological perspective. Journal of Counseling Psychology, 56(1), 3243. doi:10.1037/a0014672

Hewstone, M. (1990). The 'ultimate attribution error'? A review of the literature on intergroup causal attribution. European Journal of Social Psychology, 20(4), 311-335. doi:10.1002/ ejsp.2420200404

Hovland, C. I., \& Sears, R. R. (1940). Minor studies of aggression: VI Correlation of lynchings with economic indices. The Journal of Psychology, 9(2), 301-310. doi:10.1080/00223980.1940.991 7696

Lacerda, M. T., Pereira, C., \& Camino, L. (2002). Um estudo sobre as formas de preconceito contra homossexuais na perspectiva das re- 
presentações sociais. Psicologia: Reflexão e Crítica, 15(1), 165-178. doi:10.1590/S010279722002000100018

Lei $\mathrm{N}^{\mathrm{o}} 12.010$, de 3 de agosto de 2009. (2009, 02 set.). Diário Oficial da União. Recuperado em http://www.planalto.gov.br/ccivil_03/_ato20072010/2009/lei/112010.htm

Markus, H., \& Zajonc, R. B. (1985). The cognitive perspective in social psychology. In G. Lindzey \& E. Aronson (Eds.), Handbook of social psychology (pp. 137-230). New York: Random House.

Meyer, I. H. (2003). Prejudice, social stress, and mental health in lesbian, gay, and bisexual populations: Conceptual issues and research evidence. Psychological Bulletin, 129(5), 674-697.

Mott, L. (2003). Homossexualidade: Mitos e verdades. Salvador, BA: Grupo Gay da Bahia.

Nardi, H. C., \& Quartiero, E. (2012). Educando para a diversidade: Desafiando a moral sexual e construindo estratégias de combate à discriminação no cotidiano escolar. Sexualidad, Salud y Sociedad (Rio de Janeiro), (11), 5987. Recuperado em http://www.scielo.br/ scielo.php?script $=$ sci arttext\&pid $=\mathrm{S} 1984$ $64872012000500004 \& \operatorname{lng}=\mathrm{pt} \& \mathrm{t} \operatorname{lng}=\mathrm{pt}$. 10.1590/S1984-64872012000500004

Pacilli, M. G., Taurino, A., Jost, J. T., \& van der Toorn, J. (2011). System justification, right-wing conservatorism, and internalized homophobia: Gay and lesbian attitudes toward same-sex parenting in Italy. Sex Roles, 6(5), 580-595. doi:10.1007/s11199-011-9969-5
Patterson, C. J. (2006). Children of lesbian and gay parents. Current Directions in Psychological Science, 15, 241-244. doi:10.1111/j.14678721.2006.00444.x

Prado, M. A. M., \& Machado, F. V. (2008). Preconceito contra homossexualidades: A hierarquia da invisibilidade. São Paulo, SP: Cortez.

Rios, R. R. (2002). O princípio da igualdade e a discriminação por orientação sexual: A homossexualidade no direito brasileiro e norte-americano. São Paulo, SP: Revista dos Tribunais.

Rokeach, M. (1960). The open and closed mind. London: Basic Books.

Ross, L. (1977). The intuitive psychologist and his shortcomings: Distortions in the attribution process. In L. Berkowitz (Ed.), Advances in experimental social psychology (Vol. 10, pp. 173-220). New York: Academic Press.

Silva, A. P. R., \& Tavares, M. T. (2007). Adoção por homossexuais no Brasil. Horizonte Cientifico, 1(1), 1-22.

Uziel, A. P., Mello, L., \& Grossi, M. (2006). Conjugalidades e parentalidades de gays, lésbicas e transgêneros no Brasil. Revista Estudos Feministas, 14(2), 481-487. doi:10.1590/S0104$-026 \times 2006000200008$

Recebido: $23 / 05 / 2014$

$1^{a}$ revisão: $10 / 10 / 2014$

Aceite final: 20/10/2014 